\section{A Educação Feminina e o Ensino Reli- gioso no Colégio Progresso Campinei- ro: Reflexões a Partir da Organização do Arquivo Histórico Escolar}

\author{
Priscila Kaufmann Corrêa* \\ Maria do Carmo Martins**
}

\section{Resumo:}

O Colégio Progresso Campineiro é uma tradicional instituição escolar da cidade de Campinas (SP), fundada em 1900 destinada à formação feminina. Ao longo de sua trajetória foram reunidos muitos documentos que, a partir de 2004, foram organizados em seu acervo histórico. A constituição deste acervo envolveu diferentes sujeitos, buscando referenciar, higienizar e conservar a documentação encontrada na escola, que abrange desde os livros de matrícula até as fotografias de eventos da escola. $\mathrm{O}$ arquivo histórico do Colégio Progresso Campineiro aponta para as possibilidades renovadas de pesquisa em história da educação que busquem compreender a cultura desta escola e os elementos que a caracterizam.

Nesta perspectiva, o artigo procura trazer as possibilidades de pesquisa trazidas pelo trabalho com a organização da documentação, que mostrou as peculiaridades da formação feminina nesta instituição que, apesar de laica, adotou um forte ensino religioso.

Palavras-chave: Educação feminina, Arquivo histórico escolar, memória e história da escola.

\footnotetext{
* Priscila Kaufmann Corrêa é professora do ensino fundamental na rede municipal de Vinhedo. Possui graduação em pedagogia, é mestre em educação e doutoranda pela Faculdade de Educação da Unicamp, sob orientação da profa. Dra. Maria do Carmo Martins.

E-mail: prikco@gmail.com

**Maria do Carmo Martins é historiadora, doutora em Educação pela UNICAMP, com pós-doutorado em Educação pela University of Brighton. Professora do Departamento de Educação, Conhecimento, Linguagem e Arte da Faculdade de Educação da UNICAMP, membro do Grupo de Pesquisa Memória, História e Educação, da Red Educación Cultura y Política em América Latina e da Red Educación, Gobierno y Instituciones em Contextos Diversos.

E-mail:carminha@unicamp.br
}

Female Education And Religious Education At The Colégio Progresso Campineiro: Reflections From The Organization Of The Historical Archive
Abstract:

The Colégio Progresso Campineiro is a traditional educational institution in the city of Campinas (SP), founded in 1900 destined to female education. Throughout its history many documents that were gathered and, from 2004, were organized in its historical archive. The constitution of this collection involved different individuals, trying to reference, sanitize and maintain the documentation found in the school, which covers from the books of registration until the photographs of school events. The historical archive of the Colégio Progresso Campineiro points to the possibilities of renewed research within history of education, seeking to understand the culture of the school and the elements that characterize it.

In this perspective, the article seeks to bring research possibilities introduced by working with the organization of the documentation that showed the peculiarities of female education in this institution that, although secular, adopted a strong religious education.

Keywords: Female education, Historical school archive, memory and history of the school. 
Menino

Todos os jardins se fizeram para ti

e as flores, as pedras.

Não tentes saber mais, contempla a luz pendurada na árvore.

Quando grande não te lembrarás desta paz divina.

Mas uma obscura saudade haverá no desejo do que agora te sobra.

Joan Teixidor ${ }^{1}$

As memórias da infância costumam ser permeadas de um sentimento de nostalgia, como um tempo bom que não mais retornará. A infância figura como um momento da vida em que tudo era alegria e pureza. Tristeza e dor parecem não compor este cenário, mesmo que elas também tenham sido vivenciadas. Na poesia do Menino as memórias da criança se misturam com saudades de uma paz considerada divina, apenas possível nesta fase da vida, que não é claramente percebida pelo garoto. Esta fase da vida precisa ser vivenciada com intensidade e suas lembranças se mostram doces na fase adulta.

Além de jardins e ruas, considerados hoje bucólicos espaços de vivência da infância, espaços de brincadeiras e brinquedos, a formação da infância também se dá na escola, que mantém as crianças em suas salas por períodos cada vez mais extensos. Não surpreende, pois, que a escola também esteja entre as memórias da infância, por ser o espaço privilegiado de sua socialização. Para muitos este lugar se mostra crucial para demarcar as trajetórias na vida adulta, pelas relações que são construídas, nem sempre pacíficas.

A infinidade de narrativas vivenciadas e construídas neste espaço se mostra um rico material para o pesquisador, dando novos significados para as memórias e seus resquícios presentes nas prateleiras e armários empoeirados.

A historiografia da educação tem buscado percursos e olhares diferenciados ao debruçar-se sobre as instituições escolares e compreender seu funcionamento e a cultura que produz. Cada instituição apresenta suas particularidades, tornando o panorama educacional mais complexo e multifacetado do que as pesquisas baseadas nas ideias pedagógicas e na legislação educacional faziam supor. As instituições escolares apresentam diferentes formas de organização e de consolidação na sociedade, podendo adequar-se ou não à legislação vigente e podendo adotar os ideais pedagógicos considerados interessantes. Esta perspectiva reconhece a escola como

um espaço especializado na produção e reprodução da(s) cultura(s), consubstanciando-se, nesse sentido, num dos locais privilegiados para compreendermos as dinâmicas, os conflitos que envolvem a produção cultural em uma sociedade marcada pelas desigualdades (MARTINS, ROCHA, 2005, p. 92).

O historiador passa a buscar fontes variadas, que revelem mais sobre o interior da escola, seu funcionamento e sua organização, não se limitando a investigar as leis, decretos e resoluções referentes ao ensino. A documentação produzida pela escola, tais como livros de matrícula, históricos escolares, diários de classe, boletins, entre tantos outros papéis, constituem uma fonte rica para a pesquisa em história da educação.

A preservação dos acervos escolares ganha importância neste contexto, pois assegura a organização e a conservação da documentação histórica da instituição. O levantamento e o referenciamento dos documentos visam facilitar o trabalho do pesquisador, por oferecerem ferramentas que auxiliam na localização das fontes desejadas. Contudo, este trabalho não deve se destinar tão somente aos pesquisadores, mas à comunidade escolar como um todo, ao trazer à tona as memórias escolares e ressignificar a escola como espaço histórico, em constante transformação.

O Centro de Memória da Educação da Faculdade de Educação da Universidade Estadual de Campinas (CME/ Unicamp) teve seu projeto concebido em 2001, no interior das diferentes abordagens da história da educação, que trazem um amplo leque de questões, englobando a história das instituições escolares, as culturas da escola, a história do currículo, as memórias da escolarização, entre outras. O CME ganhou um espaço próprio no prédio da 
faculdade, para assegurar a guarda de algumas coleções e para a realização de atividades e cursos, permitindo o diálogo entre professores, pesquisadores e estudantes.

A partir do ano de 2005 o CME conseguiu o financiamento CNPq/edital Universal. para o projeto Memórias da Educação escolar: cultura material e organização de arquivos escolares, coordenado pela Profa. Dra. Maria do Carmo Martins e com a participação da Profa. Dra. Heloísa Helena Pimenta Rocha, . Com este projeto foram escolhidas duas escolas na cidade de Campinas, que tiveram seus acervos organizados: o Colégio Progresso Campineiro e o $4^{\circ}$ Grupo Escolar de Campinas, atualmente conhecida como Escola Estadual Orosimbo Maia.

O projeto envolveu pesquisadores e estudantes de diferentes áreas para a elaboração de relatórios de pesquisa, trabalhos de conclusão de curso, filmes sobre as escolas, criação de um banco de dados e dois relatórios sobre a arquitetura das instituições e seu entorno ${ }^{2}$. Este trabalho também vem sendo divulgado em diferentes eventos acadêmicos nacionais e internacionais.

Em estudos anteriores (CORRÊA, 2005; 2010; CORRÊA e MARTINS, 2006; 2008; NEVES e MARTINS, 2008) apresentamos como ocorreu a organização do acervo histórico das escolas, trazendo à tona a diversidade, a riqueza de documentos existentes e destacando as potencialidades dos estudos históricos com tais documentos.

O presente artigo retoma questões relativas ao acervo histórico do Colégio Progresso Campineiro, que foi abrigado em um espaço específico no interior da escola, permitindo o desenvolvimento de diferentes atividades envolvendo estudantes, alunos, pesquisadores e a comunidade escolar. Busca-se apresentar a experiência da constituição deste acervo e suas contribuições para pesquisas, trazendo as particularidades da educação feminina presentes naquela instituição.

Primeiramente será apresentado um breve histórico da escola, apontando para os elementos que a caracterizavam e o destaque que adquiriu no interior da sociedade campineira. O estudo da história do Colégio Progresso se mostrou um fator essencial para orientar a organização dos documentos.
O colégio oferece um conjunto rico de documentos para estudos sobre a educação feminina, que permite identificar como a instituição se fortaleceu na sociedade, legitimando a escolarização das mulheres, uma prática pouco usual na cidade no início do século XX. No caso do Colégio Progresso, o ensino religioso ganhou importância no currículo, permeando as diversas práticas do internato, apesar do estabelecimento não ser dirigido por uma congregação religiosa. Esta é apenas uma das possibilidades apresentada pela documentação da escola, sendo este um convite para novos diálogos com as fontes daquele acervo.

A exposição do contexto da criação do colégio e sua consolidação na sociedade ainda possibilitam a compreensão da lógica que norteou a preservação dos documentos, uma vez que buscam construir uma memória enaltecedora da instituição. A constituição do acervo histórico deve procurar desmistificar esta memória, sem perder de vista o caráter poético das narrativas ali construídas. Mais do que guardar documentos antigos e preciosos, o acervo precisa ser um local de circulação intensa de pessoas e ideias, permitindo o desenvolvimento de atividades de cunho acadêmico, escolar e cultural.

\section{O Colégio Progresso Campineiro}

Muitos documentos do acervo apresentam relatos sobre a fundação do Colégio Progresso Campineiro, estabelecendo o dia 08 de outubro de 1900 como o marco inicial da instituição. Conta a lenda que a menina Odila Maia teria pedido a escola de presente a seu pai, Orosimbo Maia, para não precisar sair da cidade para completar seus estudos. Assim, no dia de seu aniversário, o dia 08 de outubro, ela recebeu como presente a escola, que simboliza o conhecimento, um presente duradouro, de valor inestimável.

Entretanto, o Livro de Atas da Fundação registra que o colégio foi criado em 17 de outubro de 1900 na chácara Guanabara. O evento contou com a presença de seus fundadores, todos fazendeiros de café. Além de Orosimbo Maia, havia os senhores Tenente Coronel Arthur Leite de Barros, Luis de Campos Salles, irmão mais novo do presidente Campos 
Salles, Tenente Coronel Antonio Álvaro de Souza Camargo e Doutor Joaquim Álvaro de Souza Camargo, que foi deputado estadual e federal. Na ocasião também estavam presentes a diretora da escola, Dona Anna von Maleszewska, o corpo docente, religiosos e a imprensa local.

O grupo dos fundadores representava a elite política e econômica da cidade, interessada na escolarização das suas filhas, sobrinhas e afilhadas. A criação do colégio buscava suprir a cidade com um estabelecimento laico para o sexo feminino. Os fundadores possuíam capital suficiente para esta empreitada e criaram o Colégio Progresso na Chácara Guanabara, localizada na Avenida Barão de Itapura.

No período da Primeira República, Campinas presenciava o aumento do número de instituições de ensino criadas pelo Estado. Na década de 1930, a cidade contava com 13 Grupos Escolares, que simbolizavam um ensino público de boa qualidade graças à suntuosidade de seus edifícios e pela sua organização administrativo-pedagógica, com os alunos divididos por séries (NASCIMENTO et al., 1999, p. 45-46). Além dos Grupos Escolares foi instalada uma escola complementar em 1903, que posteriormente foi transformada em Escola Normal, conhecida como Carlos Gomes. Havia ainda a Escola Profissional Bento Quirino, criada em 1919, que oferecia cursos diurnos e noturnos. O Colégio Culto à Ciência, por sua vez, foi fundado em 1874 pela iniciativa privada e passou para a tutela do Estado em 1896. Como ginásio oficial, oferecia o curso secundário a um público seleto.

Entre os estabelecimentos particulares havia escolas que procuravam atender grupos diversos. Tais estabelecimentos podiam abranger tanto o curso primário, quanto o secundário e o profissionalizante, de acordo com os interesses dos grupos fundadores. Diversas congregações religiosas criaram instituições na cidade, como é o caso do Liceu Nossa Senhora Auxiliadora, do Colégio Diocesano Santa Maria e do Colégio Sagrado Coração de Jesus, o qual era destinado ao sexo feminino.

A escolarização se apresentava como um elemento importante para a república, uma vez que a escola garantiria a formação do cidadão republicano. Diversas classes sociais viam na formação escolar a possibilidade de ascensão social. A escolarização feminina também era defendida por permitir o acesso das mulheres a diversos ti- pos de conhecimentos, além de assegurar sua formação para desempenharem seu papel como mães e esposas. Cabia à mulher incutir os primeiros preceitos morais em seus filhos, futuros cidadãos da nação republicana.

O Colégio Progresso Campineiro não era dirigido por nenhuma congregação religiosa e destinava-se às filhas da elite campineira e da região. A primeira diretora convidada para dar forma ao projeto pedagógico da escola foi Dona Anna von Maleszewska, uma senhora austríaca com formação nas Universidades de Kiel e Nancy, na Alemanha e na França, respectivamente. Dona Anna foi diretora do Colégio Progresso de São Paulo, que encerrou suas atividades no mesmo período da fundação da escola em Campinas. A formação europeia deve ter atraído a atenção do grupo de fundadores, que buscavam oferecer uma escolarização diferenciada para suas filhas. Dona Anna permaneceu, contudo, apenas até o ano de 1902, não havendo esclarecimentos sobre seu afastamento do cargo.

Poucos são os registros referentes à Dona Anna, tratando sempre muito brevemente a sua passagem pelo colégio. Há apenas um prospecto do Colégio Progresso de São Paulo, de 1897, contendo as matérias, o enxoval e outras informações aos pais referentes à instituição de ensino dirigida por Dona Anna. No acervo do Colégio Progresso a presença de Dona Anna von Maleszewska foi apagada, diferentemente do que ocorre com Dona Emília de Paiva Meira, a segunda diretora.

Dona Emília foi convidada por Orosimbo Maia para assumir a direção da escola em 1902. Era filha do conselheiro do Império João Florentino Meira de Vasconcellos e, portanto, descendia de uma família abastada e influente. Pertencia ao mesmo meio social dos fundadores e das alunas do colégio, mostrando-se uma pessoa adequada ao cargo que exerceu.

Dona Emília Meira concluiu o curso normalista no Colégio Progresso do Rio de Janeiro, dirigido pela norte-americana Miss Eleanor Leslie Hentz (1972, p. 241). Nesta instituição Dona Emília teve aulas de matérias variadas, compondo uma formação diferenciada para mulheres à época do Império. O colégio oferecia uma gama ampla de disciplinas, incluindo ciências naturais, física, química e matemática, matérias consideradas pouco usuais para o sexo feminino. 
Em uma Lista de professores, que apresenta a relação dos docentes do Colégio Progresso Campineiro no período de 1927 a 1931, consta que Dona Emília teria prestado os exames parcelados do Colégio Pedro II no final do século XIX, a fim de obter a certificação. Este colégio servia de modelo aos demais estabelecimentos de ensino secundário e lá eram realizados os exames com bancas oficiais.

Além de ter a formação para a carreira docente, Dona Emília de Paiva Meira ainda dirigiu o Colégio Progresso em Curitiba, do qual restam no acervo os "Estatutos do Colégio Progresso dirigido por Emília de Paiva Meira", de 1897. Por motivos desconhecidos, Dona Emília precisou sair do estado do Paraná, não levando adiante o seu trabalho naquela escola. A origem abastada e a experiência docente certamente serviram de referência aos fundadores do Colégio Progresso Campineiro, que desta vez esperavam tomar uma decisão acertada.

Dona Emília Meira acabou dedicando sua vida ao colégio em Campinas, permanecendo na direção por 35 anos. Neste período tornou-se proprietária da instituição e deu forma ao seu projeto educacional. O Colégio Progresso tornou-se sua família, uma vez que não se casou e tampouco teve filhos. Seu trabalho na escola era admirado por quem a conhecia e the rendeu como homenagem uma autorização da prefeitura para enterrá-la ao lado da capela do prédio definitivo da instituição.

O Colégio Progresso passou por diferentes prédios antes de ser instalado em um prédio próprio. Após ser fundada na Chácara Guanabara, a escola foi transferida para o Palacete Anhumas, no Largo do Pará, no ano de 1904 e para o antigo edifício do Colégio Florence, na Rua José Paulino, no ano de 1908. Neste ano foi criada a Diocese de Campinas, que foi instalada no Palacete Anhumas, no qual se encontrava o colégio. Os lugares pelos quais a escola passou são relativamente próximos uns dos outros, procurando não se afastar muito de sua clientela.

O prédio da Rua José Paulino era considerado pouco adequado para atender o número crescente de alunas matriculadas e, quando Dona Emília se tornou proprietária do colégio em 1913, adquiriu um terreno no Bairro do
Frontão, atualmente conhecido como Cambuí, no ano de 1915. O prédio foi erguido na Avenida Júlio de Mesquita, que até hoje é considerada uma região nobre da cidade. O novo prédio passou a ter laboratórios, salas para aulas de música, geografia e ciências naturais, dormitórios, refeitório, enfermaria e gabinete dentário, além de recreios, pomares e um bambuzal para momentos de recreação e estudos. Neste edifício também foi instalada a capela de São Luiz Gonzaga com altar, confessionário e sacristia.

O grupo dos fundadores se desfez após vários anos buscando obter lucros com o empreendimento. O grupo encerrou a sociedade e a partir de 1907 a propriedade coube a Orosimbo Maia, até ser decidido que a diretora assumiria a escola financeiramente. O Colégio Progresso foi entregue à Dona Emília em 1913 sem dívidas e a cota de Orosimbo Maia, a única que ela precisaria pagar, não tinha prazo para ser liquidada e tampouco juros. Dona Emília adquiriu o Colégio Progresso com muitas vantagens, mas carecia de capital para manter a instituição e pagar a cota restante. Por descender de uma família de posses, a diretora recebeu de seu pai uma herança em propriedades, que a auxiliava na manutenção do colégio.

O Colégio Progresso de Campinas ganhou uma filial em Araraquara em 1924 e no ano de 1928 foi criada a Sociedade Brasileira de Educação e Instrução de Meninas (SBEIM), para manter as duas escolas. A Sociedade era composta por pessoas de confiança de Dona Emília, sendo as primeiras associadas Madame Blanc, Dona Flávia Campos da Paz, Dona Julie Villac e Dona Alda Pompêo de Camargo. Dona Flávia e Dona Julie estudaram e lecionaram no colégio e logo se tornaram auxiliares importantes de Dona Emília. Madame Henri Blanc era professora de francês antes de Dona Emília assumir a direção e ajudou a jovem diretora nos primeiros anos à frente da instituição.

Apenas mulheres católicas, solteiras e de moral ilibada podiam tomar parte ma SBEIM, assemelhando-as à condição das freiras. Mulheres casadas ou uma associada que se casasse não poderiam ser aceitas no grupo. Observa-se que a religião constituía um dos pré-requisitos para ser aceita na Sociedade, indicando sua importância na composição do corpo docente e administrativo das escolas. 
Apesar da importância desta Sociedade para o Colégio Progresso, não existem no acervo muitos documentos sobre ela. A SBEl continua funcionando até hoje na manutenção do Colégio Progresso de Araraquara, mas a própria direção afirma não possuir documentos mais antigos. O único documento doado pela direção foi o Livro de Atas da Fundação, que comprova a criação do colégio em 1900 e fornece informações sobre sua manutenção em sua primeira década. Apenas o testamento de Dona Emília de Paiva Meira fornece elementos sobre a estrutura da Sociedade, pois ali a diretora indicava suas sucessoras e os requisitos para formar parte do referido grupo.

A Sociedade criada por Dona Emília visava assegurar a manutenção do projeto educacional por ela idealizado, mesmo após seu falecimento. A indicação de mulheres que atuaram ao seu lado para continuarem sua obra como sucessoras não foi casual, uma vez que estas senhoras conheciam o projeto e o mantiveram nos mesmos moldes. Dona Julie Villac sucedeu Dona Emília Meira e foi diretora geral da SBEIM do período de 1937 a 1982.

Após o falecimento de Dona Emília Meira, o Colégio Progresso prosseguiu sua trajetória aos cuidados das pessoas indicadas pela própria diretora para darem continuidade a esta obra. Em 2002, entretanto, o Colégio Progresso Campineiro chegou a anunciar o encerramento de suas atividades. Tal possibilidade gerou manifestações por parte dos alunos e ex-alunos, que não queriam ver sua escola fechar as portas. Neste momento as Faculdades Integradas Metropolitanas de Campinas (Metrocamp) assumiram a instituição.

No ano de 2008 o antigo sócio da Metrocamp tornou-se o novo proprietário do colégio em Campinas, que, a partir do segundo semestre de 2010 passou para o grupo Anglo. Ao longo de várias décadas o projeto pedagógico do Colégio Progresso se alterou, acompanhando a legislação do ensino e as teorias educacionais em voga. Apesar das dificuldades encontradas pelo grupo de fundadores para manter a instituição em sua primeira década de funcionamento, a escola se consolidou na cidade de Campinas, tornando-se uma referência no ensino particular.

Chama a atenção ao longo desta trajetória a ênfase dada ao ensino religioso, uma vez que o Colégio Progresso não possuía qualquer ligação com alguma congregação religiosa específica, sendo sempre mantida e administrada por leigos. Contudo, ao entrar em contato com sua história através dos documentos, percebe-se que, em vários períodos, o ensino religioso ocupou importante papel na organização das práticas escolares. Dona Emília de Paiva Meira emerge, neste contexto, como figura central, que dá forma ao projeto pedagógico da escola e a estabelece a instituição na cidade. Sua presença na escola é marcante também pela documentação que restou no acervo, que inclui correspondências pessoais, seus boletins e cadernos escolares e os prospectos dos Colégios Progresso de Curitiba e do Rio de Janeiro.

Dona Emília Meira incentivou o ensino religioso na escola, garantindo a presença de religiosos para ministrarem as aulas, a catequese, as missas e comunhões. A diretora possuía boas relações com diferentes membros da lgreja católica, que viam com bons olhos a formação moral calcada na religião oferecida às moças pelo Colégio Progresso.

A pesquisa sobre o ensino religioso possibilitou-nos compreender como este ensino ocorria na escola. Investigações sobre as Associações Religiosas mostram que as meninas eram reunidas para ouvirem as exortações do padre-diretor do grupo associativista e, apenas as alunas consideradas piedosas e obedientes poderiam participar destes grupos, devendo buscar um aperfeiçoamento constante quando eram aceitas.

As associações religiosas, com seu estímulo ao bom comportamento e à obediência, se mostraram um espaço privilegiado para a formação religiosa das alunas do Colégio Progresso. Além da Pia União das Filhas de Maria, foram organizadas, naquele espaço, a Congregação dos Santos Anjos, a Liga Eucarística e o Oratório Festivo Dom Bosco. Cada Associação religiosa tinha um padre-diretor, que presidia as reuniões e era responsável pelo grupo. Este padre era escoIhido para dirigir a Associação e não tinha outros vínculos com a escola, apesar de todos eles terem boas relações com Dona Emília e exercerem importantes papéis na cidade.

Cada congregação possuía finalidades diferentes, privilegiando algumas questões religiosas, em detrimento de outras. Entretanto, permeava por todas elas um discurso 
que visava incutir nas alunas a obediência, a resignação, a pureza e a caridade. O padre, no altar, procurava exortar as meninas e moças a seguirem pelo bom caminho, utilizando-se da religião para justificar tal postura.

Todavia, percebemos também que este ensino não se limitava às associações religiosas e às aulas de religião, mas a todo um conjunto de práticas religiosas que aconteciam diariamente na escola e que fazem parte da vida do católico. Todas as alunas, professoras e funcionários do colégio precisavam participar das missas realizadas todas as manhãs e as professoras eram estimuladas a visitarem o Santíssimo Sacramento na capela, além de deverem fazer uma breve oração no começo de cada aula.

As alunas vivenciavam um ambiente de religiosidade intensa e deveriam incorporar as posturas e gestos em cada momento e espaço. O local privilegiado para as práticas religiosas era a capela de São Luiz Gonzaga, espaço sagrado para os católicos. Os religiosos que celebravam os cultos eram indicados pela Diocese, demonstrando a preocupação em seguir os preceitos da Santa Sé.

$\mathrm{O}$ acesso a alguns livros que se referiam à história sagrada, como História Sagrada do Antigo e Novo Testamento, traduzido pelo Padre José Manoel da Conceição, encontrado no acervo da escola e que data de 1890 permitiu identificar fontes provavelmente utilizadas com fim didático e conteúdos que eram valorizados neste ensino. Observou-se que o ensino religioso precisava ser compreendido de forma ampla, em suas diferentes facetas, sem perder de vista o movimento de institucionalização do Colégio Progresso Campineiro, que se consolidava na cidade. A formação moral das alunas incluía um conjunto de práticas e posturas, não se limitando às aulas de catecismo, mas que se apresentavam como um aspecto fundamental dessa escolarização feminina, uma vez que elas deveriam saber como se portar em sociedade e como educar seus filhos nos preceitos morais.

O estudo do ensino religioso do Colégio Progresso utilizou-se, pois, de diversos documentos reunidos pela escola no final do século XIX até o anode 2002. Entretanto, a documentação estava espalhada em algumas salas da escola e precisava ser organizada, a fim de facilitar a realização des- ta e de outras pesquisas. Naquele momento o trabalho de organizar a documentação se tornou fundamental, sem perder de vista a necessidade de investigar a história do colégio. O levantamento inicial das fontes para esta pesquisa teve como desdobramento a criação do Memorial do Colégio Progresso, local que guarda seu acervo histórico.

\section{O Acervo histórico do Colégio Progresso}

O trabalho com os documentos históricos foi iniciado em 2004, quando a maior parte da documentação se encontrava na sacristia da capela da escola. $O$ objetivo daquele trabalho era realizar o levantamento e o referenciamento da documentação do período de 1900 a 1937 que me auxiliasse na compreensão do ensino religioso presente na escola (CORRÊA; MARTINS, 2005).

Naquele período a Metrocamp, então proprietária da escola, reorganizava a estrutura da instituição e iniciava as atividades de seus cursos de ensino superior. $O$ arquivo da escola corresponde ao seu acervo reunido até o ano de 2002, momento em que a Sociedade Mantenedora abria mão da instituição.

Apesar do interesse do colégio em instituir um local para organizar seu acervo histórico, havia também certa resistência para termos acesso às fontes, que foram todas reunidas na sacristia da capela. Tais documentos foram conseguidos junto à antiga mantenedora, a Sociedade Brasileira de Educação e Instrução. Na sacristia estes documentos foram simplesmente amontoados em meio a outros objetos, como brinquedos, uniformes e panelas, dificultando a locomoção no pequeno espaço em $\mathrm{L}$.

A própria pesquisa foi realizada na capela, nestes momentos iniciais, uma vez que não havia outro espaço para estes documentos. Estes se mostram bastante diversificados englobando desde os papéis de Dona Emília Meira, até fotografias, recortes de jornais, livros de atas, matrícula, chamada, notas e faltas, diários de classe e prospectos de divulgação, que apontam para o movimento cotidiano da escola. 
Para Bellotto:

um arquivo permanente não se constrói por acaso. Não cabe esperar que lhe sejam enviadas amostragens aleatórias. A história não se faz com documentos que nasceram para serem históricos, com documentos que só informem sobre o ponto inicial ou o ponto final de algum ato administrativo decisivo. A história se faz com uma infinidade de papéis cotidianos, inclusive com os do dia a dia administrativo, além de fontes não-governamentais (2004, p. 27).

O arquivo permanente - ou histórico - do Colégio Progresso Campineiro abrange documentos que foram reunidos de forma a exaltar a escola e os esforços de sua diretora para mantê-la. Não é casual que exista uma grande quantidade de documentos de Dona Emília de Paiva Meira, que residiu na escola e uniu sua vida pessoal com a administração deste estabelecimento. Por outro lado, sobre Dona Anna von Maleszewska, a primeira diretora, existem pouquíssimos documentos e sua saída não é esclarecida por nenhum destes papéis. Sua passagem pela instituição dá a impressão de ter sido incômoda, pela escassez de referências a sua pessoa.

Documentos que revelassem possíveis conflitos e momentos de crise não foram encontrados na escola, causando a impressão de uma trajetória harmoniosa, vivenciada e construída pelos sujeitos que passaram pelo colégio. Esta seletividade das fontes encontradas colocou-nos vários desafios como pesquisadores, uma vez que precisávamos ficar atentas para não tornarmo-nos memorialistas oficiais da instituição. Pela prática histórica sabemos que cabe ao pesquisador atentar para estas questões, uma vez que "os textos ou os documentos arqueológicos, mesmo os aparentemente mais claros e complacentes, não falam senão quando sabemos interrogá-los" (BLOCH, 2001, p. 79). A configuração do acervo e os documentos guardados para a posteridade, devem, pois, ser analisados e estudados com cuidado.

Durante o primeiro levantamento os materiais encontrados foram divididos em três categorias: História do Colégio Progresso, Práticas religiosas e Práticas de ensino. Estes materiais foram identificados, separados e referenciados, compondo uma vasta relação da documentação referente ao período de 1900 a 1937 (CORRÊA; MARTINS, 2005). Cada documento recebeu um código, de acordo com a categoria em que foi incluído, além de haver uma breve descrição sobre seu formato e conteúdo.

O financiamento do projeto do CME, Memórias da Educação escolar: cultura material e organização de arquivos escolares, deu maior legitimidade a este trabalho de preservação da documentação histórica e, assim, o Colégio Progresso e a Metrocamp mobilizaram-se a fim de criar condições adequadas para guardar o acervo. O material foi transportado da sacristia para uma pequena sala aos fundos do colégio, um dos espaços que abrigava a antiga residência da mantenedora. Este local ficou conhecido como Memorial do Colégio Progresso, que não deveria apenas guardar a documentação, mas também permitir a realização de atividades com a comunidade escolar, divulgando e valorizando este trabalho.

Assim como acontece na maioria das atividades de localização, identificação e organização de acervos arquivísticos e bibliográficos, a documentação histórica foi encontrada em locais inadequados para sua conservação e consulta, e a atividade inicial foi, justamente, a de deslocar os documentos para espaços mais adequados de trabalho.

Em linhas gerais, o caráter eminentemente educacional de cada documento encontrado permitiu às equipes de pesquisa um trabalho de seleção e observação dessas fontes documentais, tendo como princípio de organização a preservação material da rotina escolar, conforme a época expressa nos documentos, assim como elementos que combinassem informações para a memória e a história das respectivas instituições.

A massa de documentos encontrados deve-se, parcialmente, ao trabalho de guarda por parte dos antigos administradores e professores da escola que, ao longo da história dessa instituição, movidos pelas mais distintas questões administrativas, trabalhistas e legais, optaram pelo armazenamento de documentos, obedecendo a critérios próprios de seleção e arranjo desses documentos, fato que, mesmo sem o rigor dos padrões nacionais e internacionais de organização de acervos, possibilitou a constituição dos arquivos permanentes das escolas.

Uma vez identificada a origem dos documentos, consideradas as questões de armazenamento do material de pesquisa, o tra- 
balho com os arquivos seguiu numa linha de tratamento da informação, respeitando as características dos registros documentais. Desta maneira, foi possível examinar em profundidade cada documento escolhido para análise, considerando sua tipologia, função e aplicação no contexto de trabalho.

Assim que foi determinado o modo de selecionar e dispor as informações dos documentos localizados na escola, a próxima etapa das atividades esteve direcionada para desenvolver uma análise crítica desse contexto a fim de identificar os aspectos que levassem a (re)constituir, por intermédio dos conhecimentos histórico-educacionais da equipe sobre as escolas, aliado aos princípios arquivísticos, a dinâmica interna e externa dos documentos na vida diária das respectivas unidades de ensino, pautado pelo respeito à ordem original dos fluxos de expediente.

Coube, então, aos pesquisadores analisar as características intrínsecas dos documentos, visando organizar uma versão inicial do contexto de estudo dos documentos.

Com a colaboração do arquivista Rogério Xavier Neves, foi elaborado um organograma para a identificação e organização do acervo englobando toda a documentação encontrada na sacristia. O Fundo do Colégio Progresso Campineiro reúne documentos do período de 1890 a 2002. Alguns documentos são anteriores à fundação do colégio por serem fotografias da família de Dona Emília Meira, além de terem sido encontrados alguns de seus cadernos e boletins escolares.

A elaboração do organograma representou o primeiro passo para a organização dos documentos seguindo normas arquivísticas e fornece um panorama do acervo, como pode ser observado na figura abaixo (Figura 1):

O organograma apresenta o fundo do Colégio Progresso Campineiro, que é o conjunto de todos os documentos que compõem o acervo permanente da escola, isto é, os papéis de valor histórico. Dentro do fundo, a documentação é dividida em conjuntos cada vez menores, procurando separar os materiais de acordo com suas especificidades e finalidades. $\mathrm{O}$ fundo decompõe-se, então, em grupos, sub-grupos, séries e sub-séries, quando necessário. Os grupos do Fundo do Colégio Progresso são:
FUNDO DO COLÉGIO PROGRESSO CAMPINEIRO 1900-2000

\begin{tabular}{lc} 
Administração & \\
\hline 1. Admistração Geral & 2. Setor Financeiro \\
- Certificados & - Cadernos de Despesas \\
- Notas e Faltas & - Liv. Caixa \\
- Liv. ponto & - Ações \\
- Liv. ocorrências & - Notas promissórias \\
- Liv. Inventário & - Cadernetas de poupança \\
- Regimentos Escolares & - Recibos \\
- Registro de Prof. & \\
- Liv. matrícula & 3. Sociedade Bras. de Educ. e Instrução \\
- Calendários escolares & - D. Flávia Campos da Paz \\
- Liv de conselhos & - Histórico CPC \\
- Livincineração & \\
- Folhas de freq. profs. & 4. Julie Villac \\
- Correspondência & - Docts. pessoais \\
- Boletins & \\
- Liv. chamada & 5. Emília de P. Meira \\
- Horários & - Docts. pessoais \\
- Planos de curso & \\
- Planos escolares & 6. Associações \\
- Controle de aulas & - Ex-alunas \\
- Liv. atras de exames & -Grêmios \\
- Controle de profs. & - Religiosas \\
- Processos de retenção/aprovação & - APM \\
de alunos & \\
- Liv. de atas de conselho de curso & \\
- Liv. exame adaptação & \\
- Liv. termos de visitas & \\
& \\
Práticas Escolares &
\end{tabular}

\section{Práticas Escolares}

1. Ativ. Pedagógicas

1.1 Docente

- FOA

- Diário de Classe

- Programas ens. Col. Pedro II

-Avaliação de Alunos

- Serviço de orientação Ped.

2. Ativ. Culturasis

- Salão Estud. de Arte

2. Ativ. Religiosas

- Orações

- Textos Didáticos

- Liv. de Cursos

- Liv. de Cantos

- Planos de Aula

1.2 Discente

- Liturgias e Celebração

- Trabalhos escolares

\section{Recursos Pedagógicos e Recreativos}

- Dossiês Temáticos

- Álbuns de música

- Slides

- Discos

- Mapas

\section{Iconografia}

\begin{tabular}{lc}
\hline 1. Institucionais & 2.3 Ativ. Religiosas \\
- Retratos & - Retiros \\
- Slides & - Comunhöes \\
- Dossiês de Eventos & - Santinhos \\
& 2. Arquitetura \\
2. Práticas Escolares & - Plantas \\
2.1 Ativ. Pedagógicas & - Fachada \\
- Atividades de aula & - Interior \\
- Estudos do meio & \\
2.2 Ativ. Culturasis & \\
- Festas Juninas & \\
- Exposições & \\
- Aniversários do Colégio & \\
Docts. Bibliográficos &
\end{tabular}

Docts. Bibliográficos
- Prospectos/ propagandas
- Legislação do Ensino

- Legislação do Ensino
-Jornais da Escola

- Hemeroteca

. diário oficial

grêmio

.propaganda

.eventos
Figura 1 - Organograma do Colégio Progresso Campineiro. 
Administração (ADM), Práticas Escolares (PRE), Recursos Pedagógicos e Recreativos (RPR), Iconografia (ICON) e Documentos Bibliográficos (DOB) (retângulos maiores).

No acervo a maior quantidade de documentos encontra-se no grupo referente à Administração, com papéis de valor comprobatório e que são organizados principalmente pela secretaria. Os documentos referentes às Práticas Escolares são aqueles produzidos na sala de aula e nas atividades da escola, tanto pelos professores, quanto pelos alunos, enquanto os Recursos Pedagógicos e Recreativos são os materiais utilizados para enriquecer as aulas, como slides e discos. O grupo da Iconografia engloba as fotografias e imagens, como santinhos e plantas da escola e os Documentos Bibliográficos reúnem os materiais impressos, como prospectos de propaganda e jornais.

No interior destes grupos a documentação foi subdividida em sub-grupos e séries, ou apenas em séries, permitindo identificar quais materiais estão disponíveis no acervo. Todo este trabalho procura auxiliar o pesquisador na busca pela documentação que deseja investigar, apontando o alcance do acervo, que apresenta lacunas e ausências, apesar da sua riqueza e diversidade.

O organograma foi elaborado adequando-se ao conjunto de documentos, identificando a especificidade da escola e de sua história, que foi estudada durante a organização do acervo. À documentação inicial ainda foram incorporados os materiais encontrados no arquivo permanente, que incluem documentos de cunho administrativo do início do século $X^{3}$.

Exatamente por esta configuração já existente, a primeira classificação dos documentos no Colégio Progresso seguiu modelos existentes de organização de acervos escolares, como os já estudados profundamente na Escola Caetano de Campos em São Paulo, os referenciais destacados no Centro de Referência Mário Covas (CRE) SEE/SP) e através de normas internacionais, como o ISAD (G) - General International Standard Archival Description, o ISAAR (CPF) International Standard Archival Record for corporat bodies, persons e families. Foram consultadas também as normativas do Arquivo Nacional e uma série de bibliografias específicas para dar apoio a este traba-
Iho, tais como o Manual de Trabalho em Arquivos Escolares, publicado pela SEE/SP/IMESP e o livro de BELOTTO (2004), Arquivos permanentes: tratamento documental.

Ao longo dos anos de 2006 e 2007 a documentação foi separada e organizada seguindo o organograma, que foi adaptado à medida que os conjuntos de documentos foram analisados com mais cuidado. Esta adaptação significou a criação de mais algumas séries de documentos e alguns dossiês, que consistem na reunião de documentos diversos referentes a um assunto específico. Este é o caso da documentação reunida em momentos significativos para a escola, como a comemoração de seus aniversários.

O CME ainda firmou uma parceria com o Arquivo Central do Sistema de Arquivos da Unicamp (Siarq), que disponibilizou um banco de dados para a catalogação do acervo. O banco de dados segue os conjuntos estabelecidos pelo organograma e as informações a serem inseridas sobre a documentação seguem a Norma Internacional ISAD (G) de arquivística. Com este banco de dados espera-se oferecer aos pesquisadores um sistema de busca para a localização dos documentos existentes no acervo das escolas. A inserção dos dados foi completada até o nível das séries, fornecendo um panorama amplo do acervo. Como até o momento o banco encontra-se em manutenção, sua consulta está impossibilitada.

A escolha da Norma ISAD (G) se deu em função de seu caráter internacional, que procura universalizar a descrição de cada nível dos acervos, facilitando sua busca. Isso não significa, porém, que esta Norma feche as possibilidades de adaptação dos níveis do fundo às características de cada acervo, como no caso da documentação do Colégio Progresso Campineiro (BELLOTTO, 2004, p. 182).

A constituição do organograma e do banco de dados exigiram a criação de um código para a identificação dos conjuntos de documentos. Este código começou a ser registrado nas pastas e caixas-arquivo que guardam as séries de documentos, auxiliando na sua localização. Este código segue a norma arquivística ISAD(G), identificando cada categoria do Fundo ao qual o documento pertence. A título de exemplo, tem-se para a série dos prospectos de divulgação o seguinte código: BR UNI- 
CAMP CMEFE CPC.DOB.PRO. Os campos BR UNICAMP CMEFE identificam que o fundo está localizado no Brasil, sendo de responsabilidade da Universidade Estadual de Campinas, mais especificamente do Centro de Memória da Educação. CPC é a sigla para o fundo do Colégio Progresso Campineiro, enquanto $\mathrm{DOB}$ se refere ao grupo de documentos bibliográficos e o PRO identifica a série dos prospectos de divulgação.

\section{O material fotográfico e a história oral}

Durante a organização do acervo foram priorizados os documentos dos grupos de Administração, Práticas Escolares e os Documentos Bibliográficos. As fotografias exigem um tratamento diferenciado, devido à especificidade de seu suporte. O projeto do CME possibilitou a realização de um curso, no ano de 2007, sobre Conservação e Preservação de coleções fotográficas, ministrado pela professora Marli Marcondes, do setor de Iconografia do Centro de Memória da Unicamp. O curso se mostrou importante para a identificação dos tipos de fotografias presentes no acervo.

Um trabalho inicial com esta documentação consistiu na separação das fotografias pelas séries propostas no organograma. $O$ acervo iconográfico é composto de cerca de 10 mil imagens, entre fotografias em preto-e-branco e coloridas, que datam do final do século XIX até o início do século XXI. Do final do século XIX há dois tipos de fotografias, que são as cartes de visite e as cartes cabinet, ambas consistindo em fotografias coladas em cartões, sendo as primeiras em formato de um pequeno cartão de visitas e as últimas um pouco maiores. O formato e o suporte da fotografia permitiam que fosse dada de presente pelo retratado aos seus parentes e amigos.

Ademais do trabalho com os documentos, foi criado um banco de história oral, que reúne depoimentos de diretoras, ex-alunas e outras pessoas que passaram pelo colégio. $\mathrm{O}$ acervo conta com as entrevistas de Dona Emília Albertini, que foi aluna do Colégio Progresso e diretora na década de 1940, e de Dona Amélia Palermo, que foi professora e tornou-se diretora na década de 1960, até fundar a Escola Comunitária em 1977.
O acervo ainda foi transferido por duas vezes para outras salas e, por fim, foi armazenado em um espaço reservado dentro da casa da antiga mantenedora, no qual se encontra até hoje. Este local se mostra mais adequado, uma vez que está livre da umidade nas paredes, que existia nas outras salas e atacava os documentos. Estes foram armazenados em pastas e caixas-arquivo e organizados em prateleiras de metal, materiais neutros e resistentes a insetos.

\section{Reflexões finais}

A organização do arquivo histórico escolar no Colégio Progresso Campineiro se mostrou uma atividade desafiadora pelas questões técnicas e, também, delicada sob o ponto de vista historiográfico, uma vez que nos levava a aprofundar os estudos sobre as fontes de pesquisa, os documentos que poderiam ser trazidos à luz por meio da reflexão histórica, a representação daquela escola par ao estudo das instituições escolares e, em especial, a tentativa de abrangermos melhor as categorias de cultura e práticas escolares.

Ao longo de quatro anos foi possível dar corpo ao acervo histórico do Colégio Progresso, organizando os papéis, promovendo sua higienização e buscando maneiras para assegurar a sua conservação, além de disponibilizar, a um só tempo, tanto os documentos quanto os estudos históricos realizados nesta escola. A constituição do acervo histórico mobilizou diferentes sujeitos, que contribuíram com seus conhecimentos, ideias e reflexões, todos envolvidos pelas possibilidades narrativas encontradas nos documentos e tantas vezes reelaborada.

O contato com estes documentos e também com as práticas de arquivo permitem assegurar que, além de ser uma rica fonte para as pesquisas em história da educação, que amplia seus horizontes ao se debruçar sobre a cultura produzida por estas instituições, ela sensibiliza sujeitos para a beleza da memória e da experiência vivida. $\mathrm{O}$ arquivo forneceu as principais fontes para o estudo das práticas religiosas, tema escolhido devido ao fato de percebermos, naquela instituição, contradições quanto ao caráter laico e religioso de sua trajetória, o que nos levou a valorizar os hiatos e as lacunas que, tanto por meio da narrativa oficial da 
escola quanto por meio das memórias de pessoas que por lá passaram, apareceram como nebulosas.

O ensino religioso evidenciou-se como uma particularidade do Colégio Progresso Campineiro que, como instituição laica voltada para a educação feminina, não abriu mão da religião católica para assegurar a formação moral de suas alunas. Este aspecto singular, contudo, não impediu a escola de se alinhar às exigências da legislação educacional daquele período para obter o reconhecimento do Governo Federal, oficializando a instituição.

A preocupação em atender às exigências legais, casada com uma formação religiosa intensa, consolidou a instituição na sociedade e permitiu seu reconhecimento pelas alunas, seus pais e religiosos da região. Além disso, a criação de uma Sociedade que mantivesse o projeto educacional idealizado por Dona Emília, assegurou a longevidade da instituição, assim como a preservação da documentação produzida ao longo dos anos.

Certamente pelo olhar atento do historiador às evidências, mas em especial, por suas práticas de constituir documentos em fontes, foi que conseguimos empreender tal tarefa de organizar o arquivo histórico escolar.

\section{Notas}

${ }^{1}$ TEIXIDOR, Joan. "Menino", IN: LISBOA, Henriqueta (org.). Antologia de poemas para a juventude, São Paulo: Ediouro, 2005, p. 89.

\footnotetext{
${ }^{2} \mathrm{O}$ projeto contou com a colaboração estudantes de diversas áreas. As estudantes de pedagogia Bianca J. Caetano e Carla C. Tortorelli Bizzarro, realizaram seus Trabalhos de Conclusão de Curso na E.E. Orosimbo Maia, enquanto a também estudante de pedagogia Rayane J. Aranha da Silva atuou como bolsista-trabalho do CME. O estudante de matemática Diego Fernandes G. Martins auxiliou na elaboração de um banco de dados para as fotografias da escola estadual. Os filmes "O Colégio" e"A Escola" foram elaborados pelo fotógrafo Alan Victor Pimenta, juntamente com o Prof. Dr. Milton Almeida. O estudo sobre a arquitetura das escolas foi realizado pelo arquiteto Rodrigo Martins Bryan.
}

${ }^{3} \mathrm{O}$ termo "arquivo morto" é utilizado pelos funcionários da escola mas o termo adequadamente utilizado em arquivística é arquivo permanente.

\section{Referências}

BELLOTTO, Heloísa Liberalli. Arquivos permanentes: Tratamento documental, Rio de Janeiro: Editora FGV, 2004;

BITTENCOURT, Águeda Bernadette. - "Educação escolar: Um Compromisso da Família com a Igreja" in: ALMEIDA, Ana Maria F.; NOGUEIRA, Maria Alice (orgs.). A escolarização das elites: um panorama internacional da pesquisa, Petrópolis: Vozes, 2002;

BLOCH, Marc. Apologia da História ou o Ofício do Historiador, Rio de Janeiro: Jorge Zahar Editor, 2001;

CORRÊA, Priscila K. 0 ensino religioso no Colégio Progresso Campineiro: entre prescrições e práticas (1900-1937). (mestrado), Campinas, SP: [s.n.], 2010;

CORRÊA, Priscila K.; MARTINS, Maria do Carmo. Decifra-me ou te devoro: Levantamento e Análise das Fontes sobre Ensino religioso do Colégio Progresso Campineiro na Primeira República (1900 1937). Trabalho de Conclusão de Curso, Unicamp, 2005;

Idem. "Decifra-me ou te devoro: Levantamento e Análise das Fontes sobre Ensino religioso do Colégio Progresso Campineiro na Primeira República (1900-1937)". In: ANPUH-SP Anais do XVIII Encontro de História: O Historiador e seu Tempo. Assis: Unesp/Assis, 2006. p. 01-06;

Idem. Vestígios do passado: acervo documental do Colégio Progresso Campineiro. In: Anais do II Encontro de Arquivos Escolares e Museus Escolares Curitiba: Ajir/UFPR, 2008, p. 01-16;

FILHO, Luciano M. de F.; VIDAL, Diana G. "Os tempo e espaços escolares no processo de institucionalização da escola primária no Brasil". In: Revista Brasileira de Educação, Mai./Jun./ Jul./Ago., 2000, no. 14, p. 19 - 34; HAIDAR, Maria de Lourdes M. $\mathbf{O}$ ensino secundário no Império brasileiro. São Paulo: EDUSP: Grijalbo, 1972;

HAMILTON, David. "Notas de Lugar nenhum: sobre os primórdios da escolarização moderna". In: Revista brasileira de História da Educação. Luiz Ramires (Trad.). Campinas: Editora Autores Associados, nº 1, 2001, p. 45-73; MARTINS, M. C. e ROCHA, H. H. P; Lugares de memória: sedução, armadilhas, esquecimentos e incômodos. In: Revista Horizontes, v. 7, n. 1 e 2, Editora Universitária São Francisco. Bragança Paulista: Julho/Dezembro de 2005 (pp. 91-99); 
NASCIMENTO, Therezinha A. Q. R. (et al.) Memórias da

Educação:Campinas (1850 - 1960), Campinas (SP): Editora da Unicamp, 1999;

NEVES, Rogério X. ; MARTINS, Maria do Carmo."Fontes de Pesquisas Escolares e a Formação da Memória Educacional" In: ZAMBONI, E. at all, (org.). Memórias e Histórias da Escola. 1 ed. Campinas: Mercado de Letras, (pp. 35-50).

BAEZA, Teresa Marcela M. Manual de Trabalho em Arquivos escolares, São Paulo: CRE Mário Covas, IMESP, 2003;

UHLE, Águeda. Bernadette. B. "Orosimbo Maia: Cultura e Política no Final do Século XIX" in Pró-Posições, vol. 9 n 1 [25], Campinas, março de 1998;

VINCENT, Guy; LAHIRE, Bernard.; THIN, Daniel. "Sobre a história e a teoria da. forma escolar". In: Educação em Revista, Belo Horizonte, n. 33 , p. 7-47, jun. 2001.

Recebido em 10/09/2011

Aprovado em 13/10/2011 
